\title{
Fatores influentes no desenvolvimento do potencial criativo
}

\author{
Factors that influence the development \\ of creative potential
}

Zélia Maria Freire de OLIVEIRA'

\begin{abstract}
Resumo
Estudo teórico que aborda alguns importantes fatores influentes no desenvolvimento do potencial criativo do ser humano (família, escola, ambiente de trabalho, contexto sociocultural e saúde do indivíduo), segundo as teorias sistêmicas da criatividade. As experiências familiares são fundamentais para a formação da pessoa, a constituição de valores, crenças, sentido crítico e criatividade. A escola é onde se passa grande parte da vida e, portanto, ideal para o desenvolvimento do potencial criativo, por meio de professores criativos que, valendo-se da criatividade, podem tornar suas aulas prazerosas e estimuladoras. As organizações, por sua vez, requerem indivíduos criativos, até por questão de sobrevivência no mercado. A criatividade também é influenciada pela cultura, dependendo da situação, das pessoas e de seus elementos constituintes. A saúde é vista como um processo de funcionamento integral de todo o ser, que aumenta e otimiza seus recursos, entre eles, a criatividade.
\end{abstract}

Unitermos: Aptidão. Criatividade. Desenvolvimento psicossocial.

\begin{abstract}
The article is a theoretical study that aims to provide an overview of the main influential factors in the development of creative potential in human beings (family, school, work environment, the socio-cultural context and health, according to systemic theories concerning creativity. Family experiences are essential for the formation of an individual, his values, beliefs, critical sense and creativity. People spend much of their lives in school, making it the perfect place for the development of creative potential through creative teachers who, when working with creativity, can make their lessons pleasant and stimulating. Organizations, in turn, require creative individuals, even as a matter of survival in the market. Creativity is also influenced by culture, depending on the situation, the people and its constituents. Health is seen as a process of the whole operation of the entire being, that enhances and optimizes his resources, including creativity.
\end{abstract}

Uniterms: Ability. Creativity. Psychosocial development.

mundo atual, com muito desenvolvimento tecnológico, científico, industrial e em tantas outras áreas, apresenta problemas ambientais, de saúde, de desorganização social e outros, o que requer criatividade na busca de soluções. O mercado de trabalho busca pessoas criativas que saibam inovar, agir de forma rápida, criativa, competente, indo além da competição. Como acentua De Bono (1994), não basta competir, é preciso

$\operatorname{coth}$

' Universidade Católica de Brasília, Programa de Pós-Graduação em Educação. Campus II Universitário Darcy Ribeiro, 70790-160, Braślia, DF, Brasil. E-mail: <zeliafreire@gmail.com>. 
haver o que o autor denomina "sur/petição", ou seja, correr além de, apresentar um diferencial. Essa ideia também é compartilhada por Kim e Mauborgne (2001), que acentuam que as empresas, em vez de olharem dentro dos convencionais limites que definem a sua competência, precisam olhar através deles para vislumbrar territórios ainda não ocupados, que representam um campo de inovação.

Paralelo a esse contexto mundial, as teorias recentes sobre criatividade-Teoria do Investimento em Criatividade, de Sternberg e Lubart (1996), Modelo Componencial da Criatividade, de Amabile (1996) e Perspectiva de Sistemas, de Csikzentmihalyi (1996) - segundo Alencar e Fleith (2003b), concebem a criatividade como um fenômeno sociocultural, apontando uma rede complexa de interações das variáveis do indivíduo com as da sociedade para a expressão criativa e a possibilidade de desenvolver o potencial criativo inerente a todas as pessoas, embora varie em tipo e grau, independentemente da idade, sexo ou condição social.

Pela teoria do Investimento em Criatividade, a criatividade provém de seis fatores distintos que se inter-relacionam e não podem ser vistos isoladamente: inteligência, estilos intelectuais, conhecimento, personalidade, motivação e contexto ambiental. O Modelo Componencial da Criatividade explica de que forma os fatores cognitivos, motivacionais, sociais e de personalidade influenciam o processo criativo. A Perspectiva de Sistemas focaliza os sistemas sociais e considera a criatividade um fenômeno que se constrói entre o criador e a sua audiência, e que se vale de três fatores: o indivíduo, portador de uma herança genética e de suas próprias experiências; o domínio, que é um sistema simbólico com um conjunto de regras para representação do pensar e do agir e que, em síntese, é a cultura; o campo, parte do sistema social que tem o poder de determinar a estrutura do domínio, cuja maior função é preservá-lo como tal.

Para Runco (2007), toda pessoa tem potencial para ser criativa, mas nem todas realizam esse potencial, por não terem oportunidades de desenvolvê-lo. A criatividade precisa ser exercitada com persistência, existindo para isso técnicas e estratégias de pensamento que auxiliam no desenvolvimento do potencial criativo (Alencar 2000a; Michalko, 2002; Virgolim, Fleith \& Neves84 -Pereira, 2006). Brandão, Alessandrini e Lima (1998) salientam que desenvolver o potencial criativo constitui um desafio porque o homem precisa se despir de crenças, ideias velhas e, muitas vezes, até de valores, para dar lugar ao novo; além disso, é também uma conquista, porque é a maneira de o homem, ao intuir, sentir, criar e fazer, encontrar sua essência maior, de se realizar e de exprimir o ser divino que habita sua alma. Para Michalko (2002), desenvolver o potencial criativo é ver o que ninguém mais vê, valendo-se de estratégias de saber ver e fazer com que seu pensamento se torne visível; é pensar naquilo que ninguém mais está pensando, o que envolve fluidez de ideias, fazer novas combinações, contemplar o outro lado da "moeda", vasculhar outros mundos, descobrir novas formas de busca e, enfim, despertar o espírito de colaboração.

Sendo importante desenvolver a potencialidade criativa do homem, a fim de que possa ser o continuador do mundo e expressar o seu próprio desenvolvimento (Martínez, 1997), é necessário atentar para os diversos fatores que influenciam no desenvolvimento ou na inibição da criatividade, que, segundo Runco (2007), são de diferentes espécies, incluindo-se entre eles: família, escola, ambiente de trabalho, contexto sociocultural e saúde, que foram objetos deste estudo.

\section{Fator família}

A família é o primeiro modelo para a criança: educadora, incentivadora, apoiadora e nutridora do seu desenvolvimento. Nos primeiros anos de vida, os atributos de personalidade dos pais, sua forma de agir e criar os filhos, o ambiente do lar e a forma de relacionamento são elementos de influência no desenvolvimento do potencial criativo. Se a família provê à criança experiências favorecedoras ao seu desenvolvimento criativo, estimuladoras de sua curiosidade natural e fortalecedoras de sua autoestima, certamente a criatividade aflorará com maior facilidade. Segundo Martínez (1995, p. 156) "existe um critério bastante generalizado de que a infância é o repositário das maiores potencialidades criativas do indivíduo, as quais, na maioria dos casos, longe de se desenvolver, são inibidas no decorrer da vida".

Segundo Runco (2007), a influência da família é bidirecional: os pais influenciam as crianças, por exemplo, estimulando-as a visitarem museus, contemplarem 
obras de arte; mas também as crianças podem influenciar os pais, quando demonstram interesse por algo e os pais respondem a isso. O autor pontua que a influência familiar é longitudinal e, por isso, muitas vezes difícil de ser pesquisada. Outra característica é ser intergeracional, sendo especialmente verdade que os valores familiares são passados de uma geração para outra; como exemplo, cita Johann Sebastian Bach, cuja família toda possuía talento musical.

Alencar e Fleith (2003a) salientam a importância de se estimular a imaginação da criança, sobretudo entre dois e seis anos, quando o jogo imaginativo ocorre com grande frequência; essa imaginação vai declinando à medida que se desenvolve a razão e o raciocínio. As autoras apontam como atitudes dos pais favorecedoras ao desenvolvimento criativo o relacionamento pais-criança não possessivo, o estímulo à independência e à autoconfiança, a estimulação dos interesses infantis e a promoção de condições de exploração dos seus interesses e de seu mundo interior. Como fatores inibidores citam o autoritarismo e a crítica constante.

Atitudes estimuladoras da criatividade por parte dos pais, segundo Amabile (1989), são: dar liberdade e independência com regras e limites justos; respeitar a individualidade de cada um e ensinar a expressar as emoções, porém sabendo ter controle emocional; estimular o desenvolvimento de valores; demonstrar que aprender não é somente ter notas altas; apreciar a criatividade e incentivá-la; possuir senso de humor; tecer críticas construtivas e não destrutivas - enfim, fazer do lar um lugar para a criatividade morar.

A experiência de Domino, em 1979, mostrou que um grupo de crianças, em que os pais permitiam uma maior independência aos filhos, era mais flexível e bem mais criativo do que o grupo de crianças escolhidas ao acaso (Alencar \&Fleith, 2003a). Também Esquivel e Hodes (2003) examinaram a influência da família no desenvolvimento da criatividade, constatando que os pais mais estimuladores da criatividade aceitavam a criança como indivíduo, davam-Ihe autonomia e oportunidades criativas, enquanto formavam seus hábitos e estimulavam traços da personalidade.

Embora ambientes familiares repressores, com regras rígidas de conduta e sem diálogo, sejam inibidores do potencial criativo, é interessante salientar que também lares desestruturados podem levar algumas crianças a serem criativas como uma forma de compensação às suas frustrações. É o que indica Ochse (1990): uma porcentagem importante de indivíduos com alto grau de criatividade vem de lares com dificuldades ou desfeitos. Nesse caso, a criança vê nos aspectos limitadores do ambiente uma fonte inspiradora de sua criatividade. A poetisa Cecília Meireles perdeu seus pais muito cedo e, sem ter outros irmãos, foi morar com a avó. Assim, afirmou que sua infância de menina sozinha havia the dado duas coisas que pareciam negativas, porém se tornaram positivas em sua vida: o silêncio e a solidão. Sem a companhia de outras crianças, ela mergulhou no mundo mágico das letras e da imaginação (Meireles, 1994).

Outro estudo, apontado por Lubart (2007), foi realizado por Sullway em 1999, cujo resultado sugere que os filhos primogênitos seriam menos abertos às experiências novas, mais responsáveis, organizados e eficientes do que os demais. Essas características se refletiam no plano da orientação profissional desses indivíduos, levando-os mais a profissões ligadas às ciências físicas e matemáticas, enquanto as ciências sociais e as carreiras políticas eram mais frequentes no domínio do irmão mais novo.

As experiências familiares são preponderantes para a formação da pessoa e a constituição de seus valores, crenças, sentido crítico - enfim, de sua criatividade. A criatividade na infância não é equivalente à criatividade da fase adulta, mas é difícil vislumbrar a possibilidade de um adulto criativo sem que tenha tido experiência criativa na infância (Feldman, Csikszentmihalyi \& Gardner, 1994). As entrevistas realizadas por Alencar (2008) com três pioneiros brasileiros da Psicologia Escolar demonstraram bem a influência da família no desenvolvimento da criatividade dos entrevistados, influência esta incentivadora da curiosidade e da leitura, e ainda apontaram a questão da união e estrutura da família formadora de bons hábitos.

É indiscutível a influência que a família exerce no desenvolvimento do potencial criativo, bastante assinalada pelos teóricos e suas pesquisas. Pode incentivar a criatividade ao lidar com suas crianças, ao thes fomentar o exercício da imaginação, da leitura, da curiosidade, ao lhes proporcionar meios de lidar com ambos os tipos de pensamento, divergente e convergente, ao ouvir suas histórias, prestar atenção aos seus desenhos e proporcionar um ambiente aberto ao criativo. 


\section{Fator escola}

Apesar da necessidade de pessoas criativas no mundo atual, Wechsler (2001) afirma que a criatividade ainda é um fenômeno pouco implementado nas escolas. Embora possa ser aplicada a qualquer disciplina, no cotidiano da sala de aula o professor não tem, de modo geral, estimulado a criatividade dos alunos, seja por deficiências em sua formação, desconhecimento de técnicas, procedimentos e metodologias incentivadoras da criatividade, seja pela extensão do currículo a cumprir.

Existem ingredientes necessários para uma produção criativa, que podem prover o aluno de oportunidades que o levem às ações ideais de aprendizagem (Renzulli, 1992). Para o autor, é fundamental a integração conjunta das estruturas primordiais do contexto educacional para propiciar a expansão da criatividade na escola: a) o professor, que deve ter domínio de sua disciplina e gostar do que faz; b) o aluno, cujas habilidades, estilos e interesses devem ser reconhecidos; c) o currículo, que deve ter, além da estrutura, conteúdo e metodologia, o apelo ao imaginário.

São características do professor criativo: ser aberto a novas experiências e mudanças, ser ousado e curioso, ter confiança em si próprio, trabalhar com idealismo e paixão, proporcionar clima criativo nas aulas, permitir ao aluno pensar, desenvolver ideias e pontos de vista e fazer escolhas, valorizar o trabalho criativo, não rechaçar os erros, mas torná-los pontos do processo de aprendizagem, considerar os interesses e habilidades dos alunos (Alencar, 2002, 2004; Alencar \& Fleith, 2003a, 2003b; Antunes, 2005; Fleith, 2001; Wechsler, 2001, 2002). A essa lista, Freire e Shor (1996) acrescentam que o professor precisa ser um profissional com domínio de várias capacidades e habilidades especializadas, entre elas: a) ser dialógico, pois o diálogo é em si criativo e recriativo; b) ter pensamento crítico e desenvolver tal pensamento em seus alunos; c) trabalhar o currículo de forma flexível e contextualizada; d) ser um artista, um político, um ser criativo e dinâmico, um líder, sem autoritarismo ou dominação.

Grande parte do comportamento criativo é aprendida e pode ser estimulada, afirma Fleith (2007), e por isso o professor precisa conhecer e utilizar técnicas que estimulem o desenvolvimento da criatividade, como as indicadas por Torrance (1987), Alencar (2000b), Buzan (2001), Michalko (2002), Alencar e Fleith (2003a), De La Torre (2003), e Virgolim et al. (2006). Muitas pesquisas sinalizam os bons efeitos de programas de treinamento em criatividade, entre elas a de Dias, Enumo e Azevedo Junior (2004), que investigaram os efeitos de um programa de criatividade sobre o desempenho acadêmico e cognitivo de 17 alunos com dificuldade de aprendizagem, das $2^{a}$ e $3^{a}$ séries do ensino fundamental de Vitória-ES, comparando-os a um grupo de controle. Os resultados indicaram uma melhora significativa no desempenho escolar do grupo que participou do treinamento. Os mesmos resultados positivos foram encontrados por Alencar (1975), com 791 alunos de 4a e 5 a séries. Os alunos treinados obtiveram escores mais altos em fluência, flexibilidade e originalidade do que os não treinados. Também Fleith e Alencar (1992) implementaram um programa de treinamento em criatividade com 36 alunos de $2^{\circ}$ grau e novamente foram encontrados maiores escores com o grupo treinado do que com o grupo de controle.

Apesar da importância da criatividade no contexto educacional, Alencar e Fleith (2003a) afirmam que aí persistem elementos que dificultam e, muitas vezes, inibem o desenvolvimento e a expressão da capacidade de criar, como a ênfase na reprodução do conhecimento e na memorização de ensinamentos, a indicação de apenas uma resposta correta para um problema e a pouca ênfase à imaginação e à fantasia. As mesmas pesquisadoras, em 2008, investigaram 398 professores de $1^{\text {a a }} 4^{\mathrm{a}}$ série do ensino fundamental de escolas públicas e particulares, localizadas no Plano Piloto de Brasília e em outras regiões administrativas do Distrito Federal, quanto à sua percepção sobre barreiras que dificultavam e que propiciassem condições favoráveis ao desenvolvimento da capacidade criativa de seus alunos. As barreiras mais indicadas foram um elevado número de alunos em sala de aula e alunos com dificuldades de aprendizagem.

Na trajetória de vida dos entrevistados por Alencar (2008) também se evidenciou o papel influente da escola, com professores incentivadores, que ensinavam com prazer e contagiavam seus alunos com essa paixão pelo ensinar e pelo aprender." Desde cedo, assumi meu 
interesse pela educação por acreditar no valor do conhecimento e do processo criativo do ensino e da aprendizagem como alavanca para o desenvolvimento da sociedade e da cultura"(Alencar, 2008, p.271). Também Robert J. Sternberg, ao ser entrevistado por Henshon (2008), evidenciou influências da escola em sua formação: na escola elementar, o fato de não ter se saído bem em um teste de inteligência levou-o às pesquisas que orientaram sua vida, principalmente sobre a criatividade. Ele realçou o papel do professor ao estimulá-lo a não crer em tudo que Ihe diziam, a ser questionador e curioso e partir em busca de desafios.

As pesquisas de Carvalho e Alencar (2004), Oliveira, E. (2007) e Oliveira Z. (2007) entre outras, apontaram que no âmbito escolar, embora haja reconhecimento da importância da criatividade e de se estimular o potencial criativo dos alunos, os professores e gestores pouco conhecem sobre o tema e suas técnicas, agindo mais intuitivamente.

O mundo atual exige uma nova imagem do professor e de sua atividade, pontua Vallejo (2003), sendo necessários uma escola aberta e um novo profissional que deem uma resposta criativa e responsável aos problemas da comunidade onde esta escola está inserida. Antunes (2005) enfatiza que a proposta de se incentivar a criatividade na escola não é para fazer do aluno um gênio, mas sim buscar desenvolver o potencial criativo de cada um, não para torná-lo o melhor, mas sim para torná-lo melhor.

Assim, é preciso que a escola vislumbre a criatividade como um meio de voltar a encantar os alunos, com aulas prazerosas, estimulando e desenvolvendo o potencial criativo que existe dentro de cada aluno. É preciso banir da escola as barreiras à expressão criativa, tornando-a formadora de cidadãos criativos para este mundo complexo em mudanças.

\section{Fator ambiente de trabalho}

As organizações têm se interessado pela criatividade mais do que qualquer outro setor da sociedade, segundo Alencar e Fleith (2003a), uma vez que necessitam diversificar produtos, antecipar demandas, recrutar e reter bons empregados e melhorar a qualidade de produtos e serviços, até como questão de sobrevivência no mercado. $O$ ambiente de trabalho influencia a criatividade, podendo desenvolvê-la ou inibi-la.
Sem menosprezar os componentes tecnológicos inerentes à inovação, Ponti e Ferráz (2006) afirmam que inovar depende do espírito imaginativo de indivíduos e equipes, da atitude criativa renovada e constante das pessoas e do incentivo dado pelas organizações em estabelecer, conscientemente, um clima criativo que possibilite a inovação. As organizações precisam ver a inovação como um processo estratégico. Também assinalam que, ao mesmo tempo em que o fluxo tecnológico permite resolver grande parte dos problemas existentes e futuros da humanidade e que se consolida um pensamento científico de gestão empresarial, a criatividade e a pró-atividade de sua direção revelam-se como chaves para transformar os fluxos de conhecimentos em soluções válidas para o mercado. Detectar, portanto, que perfis de gerentes são mais pró-ativos e incentivadores da inovação, os mais entusiastas e criativos, é um fator fundamental para efetivar a inovação organizacional. As organizações que têm capacidade inovadora devem gerir os seguintes subprocessos: a gerência de novos conceitos, o desenvolvimento de novos produtos e de novos processos, a gestão do conhecimento e da tecnologia (Ponti \& Ferraz, 2006). Os mesmos autores reafirmam a importância da criatividade em todas as organizações, como uma ferramenta de sobrevivência na contemporaneidade, pois para se construir o futuro é imprescindível ser criativo no presente e ser capaz de ver aquilo que ninguém mais vê, ser um visionário e inovador.

Na mesma linha de pensamento, Cornella e Flores (2007) acentuam que não há inovação sem pessoas criativas e, mais, que independentemente do setor, do tipo de organização ou de produto, o fator definitivo para que a inovação tenha lugar é a energia da pessoa criativa. É preciso, então, que a organização aproveite essa energia, proporcionando-Ihe meios para criar, "atrever-se mais", encontrar na profissão "um elemento de ruptura", dar um passo adiante e utilizar o que puder do passado, sem deixar que esse passado escravize suas ideias.

Atualmente, é muito importante o trabalho em equipes e, consequentemente, a criatividade grupal. Masi (2002) realça que a criatividade pode brotar não como fruto de um só indivíduo, mas de grupos e de coletividades. A criatividade grupal decorre da combinação das personalidades que compõem o grupo e daquilo que as motiva. 
Uma organização criativa precisa ter capacidade de adaptação, autonomia, flexibilidade, respeitar a dignidade e o valor das pessoas, intensificar a atividade de treinamento e aperfeiçoamento de seu pessoal, realizar uma administração orientada para o futuro, saber lidar com a diversidade, incorporar criativamente novos procedimentos, políticas e experiências e valorizar as ideias inovadoras (Alencar, 1997). São desafios às organizações: a) proceder às mudanças que se fazem necessárias em culturas organizacionais há muito sedimentadas, marcadas pela resistência às novas ideias e refratárias às exigências do mundo moderno; b) conscientizar os indivíduos de sua capacidade pessoal para criar, proporcionando-lhes treinamentos estimuladores da criatividade; c) promover mudanças em comportamentos que afetam de forma adversa as relações interpessoais e o clima no ambiente de trabalho; d) construir um ambiente que valorize e cultive a criatividade.

Entretanto, também nas organizações existem barreiras à criatividade: estruturais, sociais e políticas, processuais, de recursos e individuais, segundo Alencar e Fleith (2003a). Amabile (1999, p.116) acentua que é frequente ver a criatividade ser mais destruída do que estimulada: "Sufocar a criatividade é fácil. Difícil é estimulá-la". Segundo pesquisa de Bruno-Faria e Alencar (1996) com 25 funcionários de diferentes organizações, foram apontados como elementos estimuladores ou inibidores à criatividade: o ambiente físico, o sistema de comunicação empresarial, a existência de desafios, a estrutura organizacional, o estilo de trabalho e de participação, os recursos tecnológicos e materiais, os salários e benefícios, o suporte da chefia, do grupo e da organização e o treinamento.

Não basta que a pessoa passe por um treinamento ou receba instrução para que desenvolva e expresse o seu potencial criativo, é também necessário construir um ambiente que valorize e cultive a criatividade. Criatividade não é algo que acontece por acaso; ela pode ser deliberadamente desenvolvida, gerenciada, monitorada com vistas a alcançar as metas individuais e da organização. A criatividade hoje é tida como a nova moeda de mercado, como nova força motrize, decorrente disso, cresce o prestígio dos profissionais comprometidos com a inovação, o design, a imaginação e as ideias, uma classe que corresponde a 30\% da força de trabalho nos Estados Unidos e 10,9\% no Brasil (Rodri88 gues, 2007).
A criatividade no contexto do trabalho é uma necessidade organizacional de sobrevivência no mercado e de adaptabilidade ao mundo em mudança constante. Por isso, é imprescindível um clima favorável à criatividade, um ambiente que estimule os empregados a serem criativos, inovadores, participativos e parceiros na busca das metas organizacionais.

\section{Fator contexto sociocultural}

A criatividade, conforme Cropley (2006), não só é determinada por critérios sociais, mas também os determina. O produto é a face pública da criatividade e precisa ser examinado pela sociedade e receber ou não o aval dela. Ainda Cropley (2005) enfatiza que a sociedade não é simplesmente um receptor passivo dos produtos das pessoas criativas, mas ela própria determina que espécie de novidade deve ser produzida.

A cultura é um conjunto constituído por padrões de comportamento, crenças, conhecimentos, costumes, que são transmitidos de geração a geração e que distinguem um grupo social, bem como estruturam os indivíduos a interagirem com seu ambiente psíquico e social (Houaiss, 2001; Lubart, 2007). A Perspectiva de Sistemas de Csikszentmihalyi (1996) apresenta o domínio como um de seus componentes, consistindo de um conjunto de regras e procedimentos simbólicos estabelecidos culturalmente, ou seja, conhecimento acumulado, estruturado, transmitido e compartilhado em uma sociedade ou por várias sociedades; os domínios podem ser modificados mediante contribuições criativas (Alencar \& Fleith, 2003a). Um produto novo, criativo, diferente, original, pode ou não ser aceito socialmente, dependendo da cultura. Um exemplo típico disso foram as pinturas de Van Gogh, cuja genialidade só foi reconhecida após sua morte. Existem também diferenças entre as culturas. Segundo Niu e Sternberg (2002), existe uma diferença entre a cultura ocidental e a oriental no modo de encarar o que é criatividade e na definição de sua origem. No ocidente, há duas origens para a criatividade: uma baseia-se na criação bíblica por Deus e a outra na inspiração grega das musas. Na China, provém da ideia de produção e renovação infinita da natureza, as mutações do Tao, Tai-Chi ou Ying/Yang.

Também no tocante às diferenças de enfoques, os orientais incluem em suas concepções de criati- 
vidade os valores sociais e morais, o coletivismo e maior valor à conexão novo e velho. Ainda, executam atividades criativas diferentemente dos ocidentais, e as razões para isso podem estar ligadas aos valores sociais, educação e grau de modernização. Já os ocidentais tendem a focar características individuais, sucessos pessoais, gosto estético e humor.

Outras diferenças entre as culturas quanto à promoção ou inibição da atividade criativa foram analisadas por Lubart (2007). A existência de inventores, por exemplo, em uma determinada geração e sociedade, prediz o nível de criatividade das gerações subsequentes. Além disso, o autor afirma que a proximidade de vários centros de trocas e atividades culturais e industriais pode ser um incentivador de uma cultura mais criativa. Ainda para Lubart (2007), uma cultura pode: a) incentivar ou inibir a criatividade, dependendo da situação, das pessoas e de seus elementos constituintes; b) favorecer maior ou menor quantidade de atividades criativas; c) levar homens e/ou mulheres às artes; d) indicar formas que vão tomar a expressão criativa em cada área; e) modular a atividade criativa; $f$ ) permitir o afastamento das normas tradicionais pela expressão criativa; g) fazer com que a expressão criativa demonstre algumas características daquela cultura.

Os progressos recentes criaram riquezas e outros meios culturais. As modernas tecnologias provocaram mudanças quanto à forma de abordar uma tarefa criativa, e a informática possibilita novas visões criativas e novas formas de expressão (Lubart, 2007). Pode-se afirmar, com Lubart (1999), que a análise da criatividade em diversas culturas mostra que a criatividade é dependente do contexto. A cultura influencia a definição e o processo de criatividade, possuindo um conjunto de características que podem facilitá-la ou inibi-la.

\section{Fator saúde}

Osho (1999) enfatiza que a criatividade é a essência da verdadeira saúde e que todas as pessoas saudáveis são criativas. A saúde é vista como um processo de funcionamento integral de todo o ser, que aumenta e otimiza os recursos do organismo para diminuir sua vulnerabilidade aos diferentes agentes e processos causadores da doença (González Rey, 1993). Saúde, portanto, não é sinônimo de ausência de doença ou sin- tomas, mas sua definição leva a um conjunto de características relacionadas às condições biológica, subjetiva e sócio-histórica do homem. Martínez (2007) afirma que esse novo enfoque de saúde possibilita relacioná-la à criatividade. O vínculo entre criatividade e saúde é complexo e não linearmente causal. É possível vê-lo em duas dimensões: a primeira delas liga-se à emoção e afirma mesmo que "a criatividade é, antes de tudo, um importante espaço de produção de emoções"; a segunda refere-se às configurações subjetivas associadas aos processos de criatividade e de saúde. A autora aponta como consequência ser possível analisar o processo de desenvolvimento da criatividade como fonte de promoção da saúde (Martínez, 2007, p.60). Desenvolver a criatividade inclui reconhecer e definir espaços próprios e saudáveis do sujeito,"na medida em que se associam as características subjetivas relacionadas com a saúde e à produção de estados emocionais que favorecem o bem-estar do sujeito e se opõem aos processos de doença" (Martínez, 2007, p. 61).

Muitas correntes psicológicas defendem que o impulso criativo leva o homem para a ação criativa em face de conflitos e tensões, e ainda que a criatividade é um fator para a promoção da saúde mental do indivíduo (Virgolim, 2007). A autora cita Maslow que, estudando pessoas saudáveis psicologicamente, demonstrou que o homem vale-se da motivação para crescer, desenvolver-se e realizar o seu self. Também aponta May, para quem a criatividade é o encontro do ser humano intensamente consciente com o mundo, e o processo criativo é a expressão da saúde emocional da pessoa em realizar algo novo.

Conforme Runco (2007), a relação entre saúde e criatividade tem sido debatida por anos, mas frequentemente o debate tem vislumbrado apenas um lado, o que analisa a criatividade e as psicopatologias e loucura, enquanto a relação entre criatividade e saúde propriamente dita é tida como surpreendentemente complicada. Apesar das associações de criatividade à saúde, há muitos estudos sobre criadores eminentes que eram portadores de doenças mentais ou desajustes psicológicos, como o escritor francês Balzac e o cientista John Forbes Nash. Cropley (2005) pontua que a conexão entre criatividade e loucura é uma das velhas abordagens na psicologia moderna e já foi alvo de investigações empíricas há mais de cem anos atrás. Lubart (2007) aponta 
estudos que relacionaram a criatividade à perturbação mental e levanta a hipótese de que certos fatores que favorecem a criatividade seriam igualmente os fatores vulneráveis aos transtornos mentais, especialmente às psicoses maníaco-depressivas e à esquizofrenia. Entretanto, ele mesmo afirma que a equação entre inteligência criativa e pensamento psicótico é controversa.

A criatividade acontece quando há fatores ambientais estabilizantes e de contensão; porém, se os fatores ambientais são estressantes e causam desequilíbrio, a produção é incompreensível e acontecem os transtornos mentais (Lubart, 2007). Corrobora esta ideia a afirmação de Rothenberg (1990) de que, embora haja profissionais interessados em encontrar valores artísticos em insanos, isso não justifica fazer-se uma ligação entre capacidade criadora e doenças mentais.

É fato que doenças e emoções, principalmente as negativas, fazem com que a realidade seja modificada pela alteração dos filtros pessoais sensoriais e perceptivos e têm um efeito sobre a criatividade, podendo afetá-la positiva ou negativamente, alterando o processo e a produção criativa. Exemplificando, após a morte da filha Maria Julieta, o poeta Carlos Drummond de Andrade perdeu a razão de viver, a vontade de escrever e de produzir (Andrade, 2002). Cabe realçar que a saúde, sob o sentido de funcionamento total e integral do ser humano, é facilitadora da expressão criativa.

\section{Considerações Finais}

A criatividade leva a um processo de mudança e desenvolvimento pessoal e social, e deveria fazer parte da vida de cada um, bem como ser sempre incentivada em todos os ambientes onde a pessoa vive. A pessoa que quer se tornar criativa deve buscar novos caminhos, ser inovadora, ousada, curiosa, apaixonada pelo que faz e correr atrás de sonhos. Nessa caminhada são muitos os fatores influentes, sendo a família, a escola, o ambiente de trabalho, o contexto sociocultural e a saúde alguns deles, todos com importância no desenvolvimento do potencial criativo. Como enfocam as teorias sistêmicas, há outros fatores influentes que não foram tratados neste artigo, como a herança genética, as motivações intrínsecas e extrínsecas ao indivíduo, sua personalidade; entretanto, procurou-se enfocar apenas alguns fatores importantes no desenvolvimento do potencial criativo 90 do indivíduo.
Daí ser preponderante haver mais esclarecimentos sobre criatividade em todos os contextos, para que, conscientes, as pessoas possam desejar o desenvolvimento de seu potencial criativo e se desvencilhar dos mitos da criatividade. Nas instituições de ensino, é preciso que os professores sejam conscientizados da relevância de se estimular a criatividade nos alunos. Também as organizações precisam adotar visão criativa, estimulando-a em seus recursos humanos, até por questão de sobrevivência nesse mercado cada vez mais competitivo.

Não são todas as pessoas que possuem a capacidade de fazer algo grandioso, notável, como os grandes gênios e ganhadores do prêmio Nobel, mas todas possuem um potencial criativo dentro de si, podendo desenvolvê-lo e usar essa capacidade criadora em sua própria vida, no seu trabalho, no seu cotidiano.

Criatividade ainda é um tema que necessita mais pesquisas e, inclusive, o estudo sobre os fatores influentes no desenvolvimento do potencial criativo, que são muitos. Mesmo assim, já é possível perceber que é preciso investir na criatividade das pessoas, divulgar mais o assunto, para que se conscientizem de sua importância e possam buscar meios para seu desenvolvimento, de modo que os ambientes frequentados pela maioria das pessoas possam contribuir para que sejam mais criativas.

Concluindo, fica o convite para que todas as pessoas busquem desenvolver o seu potencial criativo e conheçam técnicas que Ihes possibilitem alcançar esse desenvolvimento, pois a criatividade é acessível a todos e são muitos os desafios e problemas do mundo contemporâneo que carecem de respostas criativas.

\section{Referências}

Alencar, E. L. S. (1975). Efeitos de um programa de criatividade em alunos de $4^{a}$ e $5^{a}$ séries. Arquivos Brasileiros de Psicologia, 27, 3-15.

Alencar, E. M. L. S. (1997). A gerência da criatividade. São Paulo: Makron Books do Brasil.

Alencar, E. M. L. S. (2000a). O perfil do professor facilitador e do professor inibidor da criatividade segundo estudantes de pós-graduação. Boletim da Academia Paulista de Psicologia, 19 (1), 84-94.

Alencar, E. M. L. S. (2000b). O processo da criatividade. São Paulo: Makron Books do Brasil. 
Alencar, E. M. L. S. (2002). O contexto educacional e sua influência na criatividade. Linhas Críticas, 8 (15), 165-178.

Alencar E. M. I. S. (2004). Como desenvolver o potencial criador. Petrópolis: Vozes.

Alencar E. M. I. S. (2008). A trajetória de vida de três pioneiros brasileiros da psicologia escolar. Psicologia Escolar Educacional, 12 (1), 265-278.

Alencar, E. M. L. S., \& Fleith, D. S. (2003a). Criatividade: múltiplas perspectivas (3a. ed.) Brasília: EdUnB.

Alencar, E. M. L. S., \& Fleith, D. S. (2003b). Contribuições teóricas recentes ao estudo da criatividade. Psicologia: Teoria e Pesquisa, 19 (1), 1-8.

Amabile, T. M. (1989). Growing up creative. Buffalo, NY: The Creative Education Foundation.

Amabile, T. M. (1996). Creative in context. Boulder, CO: Westview Press.

Amabile, T. M. (1999). Como não matar a criatividade. HSM Management, 3 (12), 110-117.

Andrade, C. D. (2002). Sentimento do mundo (2a. ed.). Rio de Janeiro: Record.

Antunes, C. (2005). A criatividade em sala de aula. Petrópolis: Vozes.

Boden, M. A. (1999). Dimensões da criatividade. Porto Alegre: Artmed.

Brandão, C. R., Alessandrini, C. D., \& Lima, E. P. (1998). Criatividade enovas metodologias (Série temas transversais, 4). Peirópolis: Fundação Peirópolis.

Bruno-Faria, M. F., \& Alencar, E. M. L. S. (1996). Estímulos e barreiras à criatividade no ambiente de trabalho. Revista de Administração da USP, 31 (2), 50-61.

Buzan, T. (2001). O poder da inteligência criativa. São Paulo: Cultrix.

Carvalho, O., \& Alencar, E. M. L. S. (2004). Elementos favorecedores e inibidores da criatividade na prática docente, segundo professores de geografia. Psico, 2 (35), 213-221.

Cornella, A., \& Flores, A. (2007). La alquimia de la innovación. Barcelona: Deusto.

Cropley, A. J. (2005). Creativity, in education and learning: a guide for teachers and educators. London: Routledge Falmer.

Cropley, A. J. (2006). Dimensions of creativity. Roeper Review, 28 (3), 125-130.

Csikszentmihalyi, M. (1996). Creativity. New York: Harper Collins.

De Bono, E. (1994). Criatividade levada a sério. São Paulo: Livraria Pioneira.

De La Torre, S. (2003). Dialogando com a criatividade. São Paulo: Madras.

Dias, T. L., Enumo, S. R. F., \& Azevedo Junior, R. R. (2004). Influências de um programa de criatividade no desempenho cognitivo e acadêmico de alunos com dificuldade de aprendizagem. Psicologia em Estudo, 3 (9), 429-437.

Esquivel, G. B., \& Hodes, T. G. (2003). Creativity, development and personality. In J. Houtz (Org.), The educational psychology of creativity (pp.135-165). Cresskill, N.J.: Haptom Press.

Feldman, D. H., Csikszentmihalyi, M., \& Gardner, H. (Orgs.). (1994). Changing the world: a framework for the study of creativity (pp. 69-84). Westport, CT: Praeger.

Fleith, D. S. (2001). Criatividade: novos conceitos e idéias, aplicabilidade à educação. Revista Cadernos de Educação Especial, 17, 55-61.

Fleith, D. S. (2007). A promoção da criatividade no contexto escolar. In A. Virgolim (Org.), Talento criativo: expressão em múltiplos contextos (pp.145-157). Brasília: EdUnB.

Fleith, D. S., \& Alencar, E. M. L. S. (1992). Medidas de criatividade. Psicologia: Teoria e Pesquisa, 3 (8), 319-326.

Freire, P., \& Shor, I. (1996). Medo e ousadia: o cotidiano do professor. São Paulo: Paz e Terra.

Gardner, H. (1994). The creators' patterns. In M. Feldman, M. Csikszentmihaliy \& H. Gardner (Orgs.), Changing the world: a frameworkfor the study of creativity (pp.69-84). Westport, $\mathrm{CT}$ : Praeger.

González Rey, F. (1993). Salud, personalidad y modo de vida. Caracas: Fondo Editorial de la Faculdad de Humanidades de la Universidad Central de Venezuela.

Henshon, S. (2008). Adventurous navigator of the dimensions of high abilitlity: an interview with Robert J. Sternberg. Roeper Review, 30 (2), 75-80.

Houaiss, A. (2001). Dicionário Houaiss da língua portuguesa. Rio de Janeiro: Objetiva.

Kim W. C., \& Mauborgne, R. (2001). Creating new market space. In Harvard business review on innovation (pp.1-30). Boston: Harvard Business School Publishing Corporation.

Lubart, T. (1999). Creativity across cultures. In R. J. Sternberg (Org.), Handbook of creativity (pp.339-350). New York: Cambridge University Press.

Lubart, T. (2007). Psicologia da criatividade. Porto Alegre: Artmed.

Martínez, A. M. (1995). Como desarrollar la creatividad em la escuela. In A. M. Martínez (Orgs.), Pensar y crear: estrategias, programas y métodos (pp.156-208). Havana: Editorial Academia.

Martínez, A. M. (1997). A criatividade, personalidade e educação. São Paulo: Papirus.

Martínez, A. M. (2007). Criatividade e saúde nos indivíduos e nas organizações. In A. Virgolim (Org.), Talento criativo: expressão em múltiplos contextos (pp.53-64). Brasília: EdUnB.

Martins, E. (2002). Ciência hoje das crianças 2002. Recuperado em 31 maio, 2004, disponível em http://www.2.vol. com.br/cienciahoje/che/drumond2.htm

Masi, D. (2002). Criatividade e grupos criativos. Rio de Janeiro: Sextante.

May, R. (1982). A coragem de criar (3a. ed). Rio de Janeiro: Nova Fronteira.

Meireles, C. (1994). Poesia completa. Rio de Janeiro: Nova Aguilar. 
Michalko, M. (2002). Los secretos de los genios de creatividad. Barcelona: Gestión 2000.com.

Niu, W., \& Sternberg, R. (2002). Contemporary studies on the concept of creativity: the east and the west. The Journal of Creative Behavior, 36 (4), 269-284.

Ochse, R. (1990). Before the gates of excellence: the determinants of creative genius. New York: Cambridge University Press.

Oliveira, Z. M. F. (2007). Criatividade na formação de professores do curso de letras. Dissertação de mestrado não-publicada, Universidade Católica de Brasília.

Oliveira, E. L. L. (2007). Criatividade e escola: uma articulação necessária limites e possibilidades segundo gestores e orientadores educacionais. Dissertação de mestrado não-publicada, Universidade Católica de Brasília.

Ponti, F., \& Ferraz, X. (2006). Pasión por innovar. Barcelona: Granica.

Renzulli, J. S. (1992). A general theory for the development of creative productivity in young people. In F. Mönks \& W. Peters (Orgs.), Talent for the future (pp.51-72). Assen/ Maastricht, The Netherland: VanGorcum.

Rodrigues, C. (2007, junho 1). Criatividade é a nova moeda. Jornal ValorEconômico, Caderno especial defim desemana, 348, 4-7

Rothenberg, A. (1990). Creativity and madness: new findings and old. Baltimore, MD: John Hopkins University Press.
Runco, A. M. (2007). Creativity, theories and themes: research, development, and practice. San Diego: Elsevier.

Sternberg, R., \& Lubart, T. (1996). Investing in creativity. American Psychologist, 51 (7), 677- 688.

Torrance, E. P. (1987). Teaching for creativity. In S. G. Isaksen \& S. G. (Orgs.), Frontiers of creativity research: beyond the basics (pp.189-215). Buffalo, NY: Bearly Limited.

Vallejo, J. M. B. (2003). Escola aberta e formação de professores. Rio de Janeiro: DP\&A.

Virgolim, A. (2007). Prefácio. In A. Virgolim (Org.), Talento criativo: expressão em múltiplos contexto (pp.19-27). Brasília: EdUnB.

Virgolim, A. M. R., \& Fleith, D. S., \& Neves-Pereira, M. S. (2006). Toc, toc... plim, plim! Campinas: Papirus.

Wechsler, S. M. (2001). A educação criativa: possibilidade para descobertas. In S. Castanho, S. \& M. E. Castanho (Orgs.), Temas e textos em metodologia do ensino superior (pp.165-170). Campinas: Papirus.

Wechsler, S. M. (2002). Criatividade: descobrindoeencorajando. Campinas: Livro Pleno.

Recebido em: 4/6/2008

Versão final reapresentada em: 18/6/2009

Aprovado em: 3/9/2009 